\title{
FLUJOS DE INFORMACIÓN VISUAL, INTERACCIÓN SOCIAL Y PINTURAS RUPESTRES EN EL DESIERTO DE ATACAMA (NORTE DE CHILE) ${ }^{1}$
}

\author{
Francisco Gallardo, ${ }^{2}$ Gloria Cabello, ${ }^{3}$ Gonzalo Pimentel, ${ }^{4}$ Marcela Sepúlveda ${ }^{5}$ y Luis Cornejo ${ }^{6}$
}

\begin{abstract}
Resumen
El presente artículo explora la interacción social en la región atacameña a partir del estudio de sus pinturas rupestres. Mediante el estudio cuantitativo y cualitativo de las distribuciones pictóricas, tanto por las estructuras compositivas como por los íconos claves que aparecen simultáneamente en dos o más localidades rupestres, se determinan flujos diferenciales de información visual. Esta circulación

de conocimiento y personas habría operado como expresión de relaciones sociales preferenciales entre las distintas comunidades del
\end{abstract} desierto de Atacama.

Palabras claves: interacción social - pinturas rupestres flujos de información visual.

\begin{abstract}
This article explores social interaction in the Atacama region through the local rock art paintings. Using a quantitative and qualitative study

of pictorial distribution, including both compositional structures

and key icons that appear simultaneously in two or more areas with

rupestrian art sites, we can determine the presence of differential

visual information flows. This flow of knowledge and people would

have operated as an expression of preferential social relations between the different Atacama Desert communities.
\end{abstract}

Key words: social interaction - rock art paintings visual information flows.

Recibido: diciembre 2011. Aceptado: marzo 2012.

\section{* Introducción}

"Yo no puedo ver algo sin copiarlo", confesó una alfarera mexicana frente a la decoración de las cerámicas producidas por otros talleres artesanales de su comunidad, mientras visitaba una feria en San José de Michoacán (Friedrich 1970: 337). San José tiene un número importante de productores cerámicos $y$, aunque las decoraciones son distintivas de cada grupo de trabajo (e incluso entre alfareros individuales), ellos están abiertos a la adopción de clases de diseño y composición que introducen de manera particular en sus propias obras. Se trata de flujos de información visual y variabilidad estilística que también han sido registrados en el suroeste norteamericano (p.e., Plog 1978) y en el Amazonas peruano (De Boer y Moore 1982; De Boer 1990). Es un proceso de transmisión de conocimientos que depende directamente de la circulación de objetos y/o personas, desplazamientos que están determinados por redes de interacción social cuya amplitud y formas varían de acuerdo al modo e intensidad de las relaciones económicas y sociales existentes entre personas y comunidades a nivel intra e interregional.

Dadas las extremas condiciones ambientales del desierto de Atacama en el norte de Chile, con tasas bajas de precipitación y altas de insolación, los recursos que permiten el sostenimiento humano se distribuyen en parches discontinuos, circunscripciones ambientales alimentadas por ríos de origen cordillerano y aguas subterráneas

\footnotetext{
1 Proyecto FONDECYT 1070083.

2 Museo Chileno de Arte Precolombino. Bandera 361, Santiago, CHILE. Email: fgallardo@museoprecolombino.cl

3 Centro de Investigaciones del Hombre en el Desierto. Av. General Velásquez 1775, Of. 403, Arica, CHILE. Email: glcabello@gmail.com

4 Universidad Católica del Norte. Gustavo le Paige 380, San Pedro de Atacama, CHILE. Email: gpimentel@ucn.cl

5 Universidad de Tarapacá. Departamento de Antropología, 18 de Septiembre 2222, Casilla 6D, Arica, CHILE. Email: msepulveda@uta.cl

6 Museo Chileno de Arte Precolombino. Bandera 361, Santiago, CHILE. Email: Icornejo@museoprecolombino.cl
} 


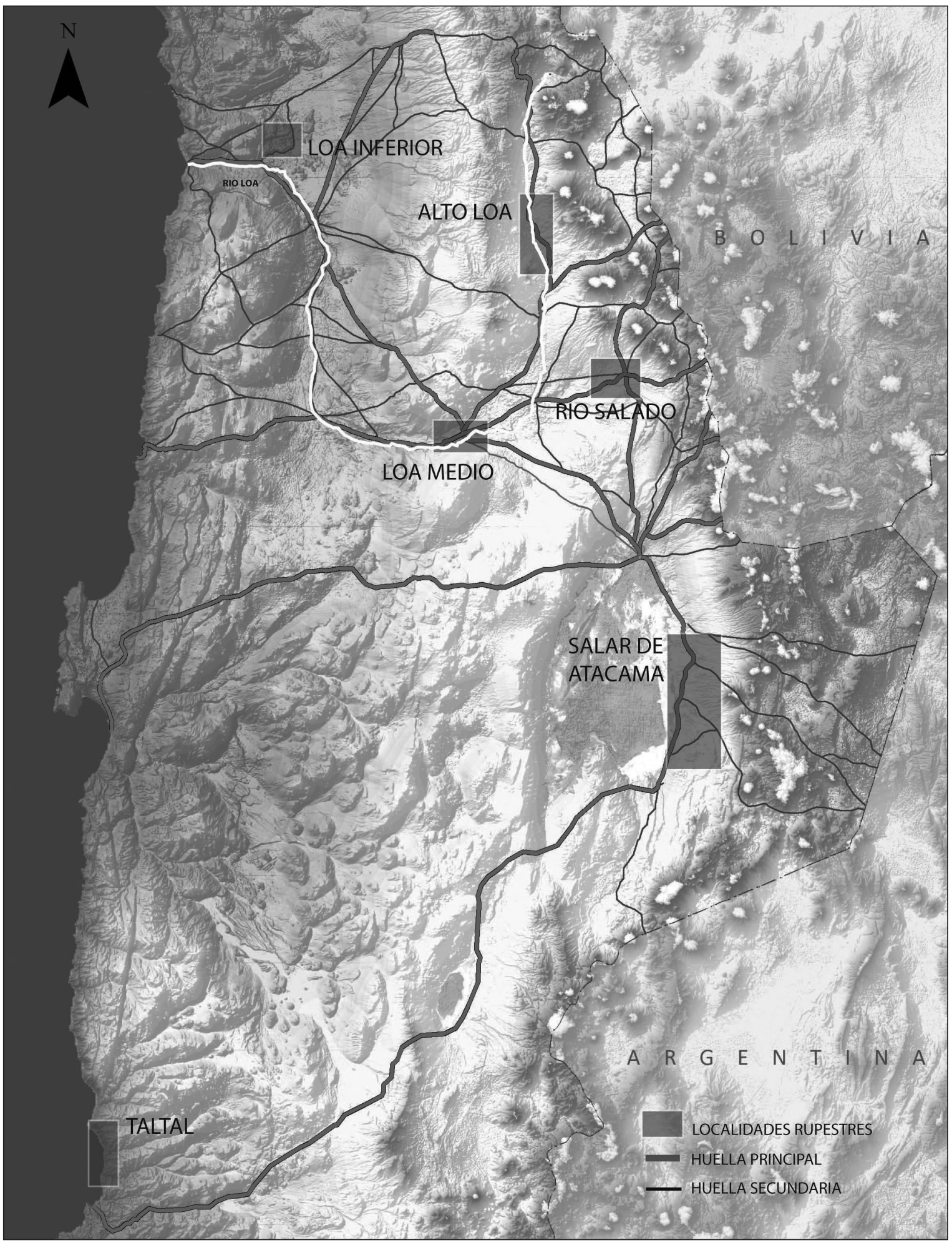

Figura 1. Ubicación geográfica de las áreas incluidas en el estudio. 
(Marquet et al. 1998). Mientras en la costa desértica los asentamientos estuvieron asociados a aguadas, en el interior y por sobre los 2.000 m.s.n.m., las comunidades se emplazaron junto a los ríos y vegas regadas por aguas subterráneas. Excepción a este patrón ambiental es el río Loa, único curso de agua que drena al océano Pacífico, donde los ambientes de ribera disponibles fueron densamente ocupados.

Estos ambientes favorecieron el establecimiento persistente de un variado número de comunidades que, de acuerdo a la arqueología y etnohistoria regional mantuvieron relaciones entre sí desde el Arcaico Medio (6.000 - $3.500 \mathrm{AC}$ ) hasta inicios del período Colonial (ca. 1.536 DC) (p.e., Agüero et al. 2006; Berenguer 2004; De Souza 2004; De Souza et al. 2007; Cases et al. 2008; González y Westfall 2010; Llagostera 1996; Martínez 1985a; Núñez 1971, 1984a, 1992; Pollard 1970; Sinclaire 2004; Uribe 2006; Uribe y Ayala 2004). Los modelos de interacción social vigentes sugieren que los vínculos se hicieron efectivos mediante caravanas de llamas que articulaban y redistribuían recursos de distintos pisos ecológicos, mediante desplazamientos pedestres en el perfil costa-cordillera y el acceso directo a través del doble domicilio (p.e., Hidalgo 1984; Llagostera 1996; Martínez 1998; Núñez y Dillehay 1995; Pimentel et al. 2011). Aunque las evidencias para la mayoría de estas modalidades de circulación de personas, bienes e ideas durante la prehistoria son indirectas, es concluyente la idea de que tales relaciones intercomunales fueron parte constitutiva de la vida social en el pasado, en especial si se considera la vasta red de caminos prehispánicos que articulan la región (Figura 1).

El arte rupestre en esta área es especialmente abundante y se extiende desde la costa hasta los valles del interior (p.e., Mostny y Niemeyer 1983) (ver Figura 1). También presenta gran diversidad técnica y formal, sin embargo, las obras de mayor cobertura regional están realizadas mediante pintura. Más aún, estas representaciones pintadas son los artefactos visuales inmuebles que exhiben el mayor número de atributos o decisiones técnicas a nivel productivo y de diseño (p.e., Berenguer 2004a; Gallardo et al. 1999; Núñez et al. 1997; Núñez y Contreras 2006). Los motivos son especialmente importantes por su contenido iconográfico y por los arreglos compositivos que organizan dos o más de estas unidades gráficas, cuyas estructuras suelen ser escénicas o simétricas (Gallardo 2009a). Entenderemos por escena una representación cuyos motivos están ligados entre sí por relaciones de actividad (p.e., la caza de un animal) y por simetría, los arreglos espaciales caracterizados por movimientos y las repeticiones de motivos - equivalentes en forma y tamaño- a partir de un punto o una línea (Gallardo 2009a).

En arqueología, una localidad corresponde a un territorio limitado cuya diversidad funcional de sitios es equivalente a una comunidad, por consiguiente, consideraremos como una localidad rupestre a aquel conjunto de sitios parietales contenidos por dicha unidad espacial. En la región atacameña, los estilos pictóricos de cada localidad tienden a ser variables y característicos, a diferencia de los grabados cuyos estilos -donde domina el agregado como recurso de disposición- tienden a aparecer simultáneamente en dos o más de estas unidades. Esto ocurre con los estilos Kalina (Arcaico Tardío) - con numerosos paneles en el Alto Loa y algunos en Puripica en las cercanías del oasis de San Pedro de Atacama-, Taira Tulan (Formativo Temprano) y Quebrada Seca (Tardío), cuya cobertura sobre las quebradas altas es de carácter regional (p.e., Berenguer 2004b; Gallardo 2001, 2009b; Sepúlveda 2002). La tendencia pictórica general en cada localidad es la particularidad y persistencia en lo formal, pues mientras en cada período hay nuevas iconografías, las fórmulas de diseño se mantienen contribuyendo a una historia visual local.

En el presente artículo, intentaremos esbozar los flujos de información visual precisando las distribuciones pictóricas tanto por las estructuras compositivas como por los íconos claves que aparecen simultáneamente en dos o más localidades rupestres. Las distribuciones pictóricas serán objeto de un análisis cuantitativo para establecer relaciones estadísticamente significativas y las estructuras compositivas serán analizadas a través de un estudio cualitativo orientado a determinar correspondencias en el orden de la forma visible. Partimos del supuesto de que a mayor interacción entre localidades, mayor serán las semejanzas estructurales e iconográficas, asunto que la etnoarqueología sugiere ser el resultado de la circulación de personas, quienes, en nuestro caso de estudio, tuvieron acceso a un repertorio de imágenes y contenidos de artefactos inmuebles propios de localidades distintas a las suyas. Esta copresencia rupestre opera instrumental- 
mente como un proxi de creencias compartidas respecto a la construcción de los paisajes visuales habitados por los sujetos en el pasado y que tiene un valor de integración social intercomunal (ver Gamble 1982; Wobst 1977). Sabemos que, durante la prehistoria, las comunidades del desierto de Atacama mantuvieron constantes relaciones expresadas por los flujos de bienes, sin embargo, seguiremos aquí las sugerencias del registro etnohistórico para el período Colonial Temprano, que indica la presencia de un dispositivo de relaciones preferenciales entre las diferentes comunidades de la región y otras de áreas vecinas (p.e., Martínez 1990). Por ejemplo, mientras las gentes del altiplano boliviano aparecen registradas en el Loa Medio (Calama y Chiuchiu) y sus afluentes (río San Pedro y río Salado), aquellos procedentes de Tarapacá (Pica y Guatacondo) solo aparecen en la primera ecozona. Se trata de una orientación de acceso social diferencial que también pudo afectar a quienes habitaban las diferentes localidades de la región atacameña.

\section{* Las localidades rupestres}

El desierto de Atacama es probablemente una de la regiones más importantes en pinturas rupestres de Chile, obras cuyos estilos y distribución espacial son bien conocidas (p.e., Berenguer 2004a; Gallardo et al. 1999; Niemeyer 2010; Núñez et al. 1997; Sepúlveda 2002) (Figura 2). El norte de esta región limita con el río Loa, que baja desde la Puna sobre los 4.000 m.s.n.m. hasta la costa desértica. En su hoya hidrográfica y curso principal se han registrado un conjunto de localidades caracterizadas por numerosos paneles de pinturas rupestres. En su sección superior, se reconocen dos localidades rupestres: el Alto Loa y el río Salado, su principal afluente cordillerano. La primera trátase de una profunda quebrada de amplia superficie apta para el pastoreo y la agricultura, y se caracteriza por grandes diseños zoomorfos y antropomorfos (entre 1 y $4 \mathrm{~m}$ de altura), realizados con pigmentos rojos sobre el farellón rocoso que son adscritos a los estilos

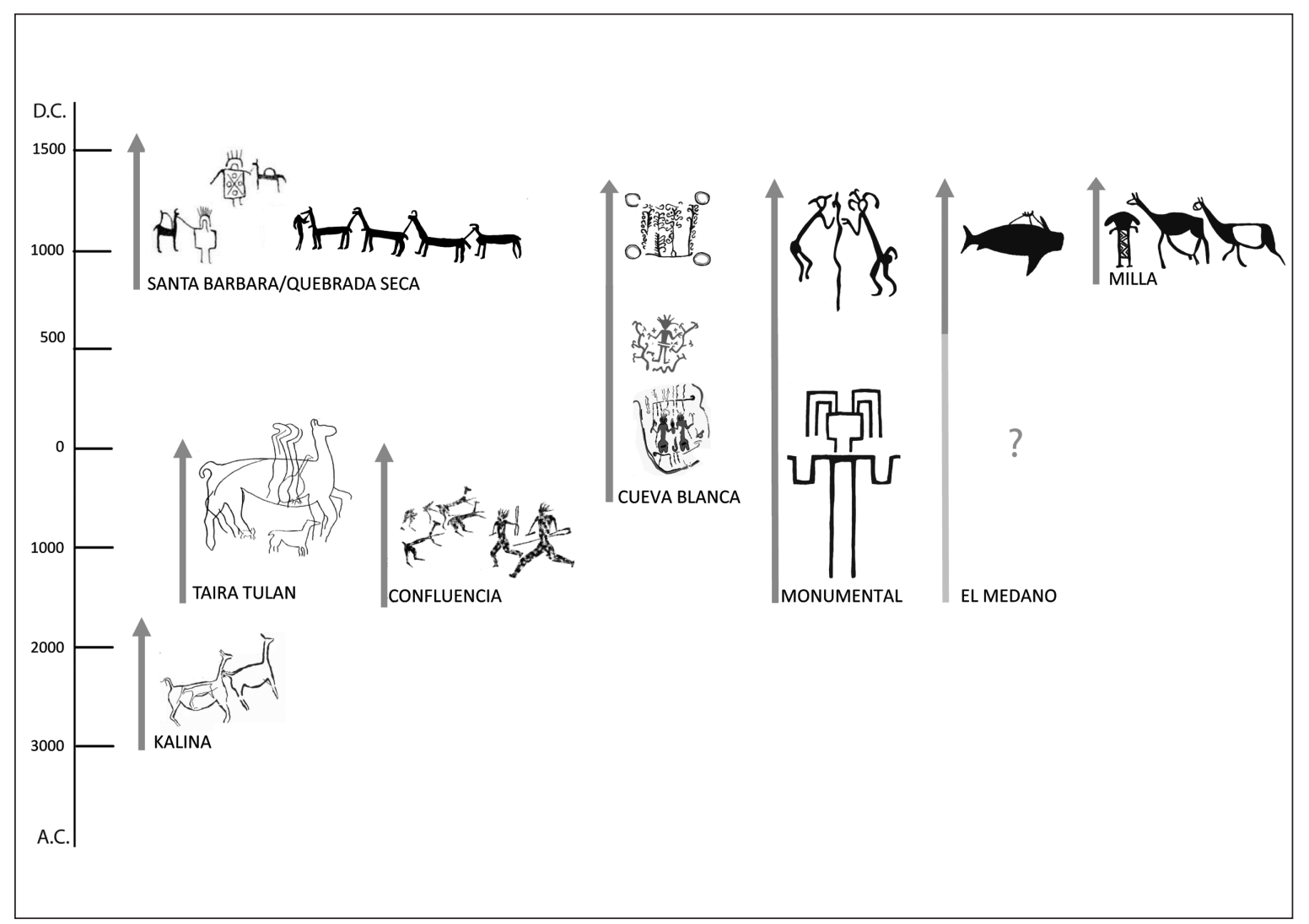

Figura 2. Cronología de los estilos de arte rupestre de la región atacameña. 
Milla (Intermedio Tardío) y Monumental (Formativo Temprano/ Intermedio Tardío). En menor proporción, se hallan aleros con personajes ataviados con túnicas policromas, caravanas de llamas en negro y otras figuras en rojo relacionadas al estilo Santa Bárbara (Intermedio Tardío/Tardío) (Berenguer 2004a, 2004b; Horta 2001).

En la localidad de Río Salado, las pinturas se encuentran en su mayoría en abrigos rocosos asociados a las quebradas y exhiben al menos tres estilos pictóricos dominantes. El más antiguo corresponde al estilo Confluencia (Formativo Temprano), con figuras confeccionadas en pigmentos rojos de pequeño tamaño (entre 15 y $20 \mathrm{~cm}$ ), donde el número de humanos es doblado por camélidos silvestres cuyas formas retienen aspectos de la anatomía corporal, se muestran de perfil, en animación o con efectos de movimiento que suelen aparecer en conjuntos que forman escenas (Gallardo 2001; Gallardo y Yacobaccio 2005). En menor proporción aparecen composiciones policromas organizadas de acuerdo a principios de simetría, conjuntos rupestres que pertenecen al estilo Cueva Blanca (Formativo Medio/ Formativo Tardío), al igual que otro grupo de pinturas de mayor diversidad estilística cuya iconografía se asocia al período Intermedio Tardío y Tardío Regional (Gallardo 2009a; Sepúlveda 2002 y 2006). Para el primero, se identifican tres modalidades estilísticas, generalmente de pequeño tamaño y ubicadas en espacios restringidos, relacionadas con diferentes prácticas y ámbitos de la vida cotidiana (Sepúlveda 2011).

Aguas abajo sobre los 2.000 m.s.n.m., en las inmediaciones de la ciudad de Calama, la localidad rupestre de Loa Medio exhibe, en pared de quebrada y abrigos rocosos, pinturas monocromas y policromas que podrían estar relacionadas a los períodos Formativo Medio e Intermedio Tardío. Las primeras muestran personajes frontales con tocados radiales y las segundas, largas túnicas o camisones.

A unos $30 \mathrm{~km}$ de la desembocadura del río Loa, se localiza Quebrada Amarga (localidad de Loa Inferior), donde recientemente se han descubiertos tres sitios en pared rocosa con figuras de animales marinos y antropomorfos que recuerdan el estilo costero El Médano. El sitio que da nombre a este estilo, con pinturas en quebradas cordilleranas, más aleros en la franja litoral conforman la localidad de Taltal, situada unos $200 \mathrm{~km}$ al sur en las cercanías del puerto homónimo. Allí son frecuentes las escenas de caza y arrastre de grandes presas marinas que pudieron estar vigentes desde el 1.000 AC (Niemeyer 2010; Núñez y Contreras 2006).

La última localidad rupestre se sitúa al oriente del salar de Atacama en un sistema de quebradas precordilleranas, donde se conocen aleros y algunas paredes rocosas con pinturas cuyos estilos son en lo general los mismos que en el río Salado.

Sucesivas temporadas de campo nos han permitido el registro de todos los sitios con pinturas rupestres conocidos (Tabla 1) a través de un amplio inventario que incluye tanto los motivos individuales como las composiciones. Estas últimas fueron descritas de acuerdo a un protocolo que permitió el análisis estadístico comparativo, mientras los motivos unitarios fueron analizados cualitativamente en función de su iconografía.

\begin{tabular}{|l|c|c|}
\hline Localidades & $\begin{array}{c}\text { N Motivos } \\
\text { Simples }\end{array}$ & N Motivos Compuestos \\
\hline Alto Loa & 448 & 37 \\
\hline Loa Medio & 85 & 8 \\
\hline Loa Inferior & 115 & 83 \\
\hline Río Salado & 666 & 58 \\
\hline Salar de Atacama & 378 & 416 \\
\hline Taltal & 1575 & \\
\hline
\end{tabular}

Tabla 1. Total de motivos simples y motivos compuestos, Región Atacameña.

\section{* Composiciones rupestres y análisis ESTADÍSTICO COMPARATIVO}

Para el estudio estadístico de comparación entre las localidades de Quebrada Amarga (Loa Inferior), Loa Medio, Alto Loa, Río Salado, salar de Atacama y El Médano, se consideraron las siguientes variables, cuyo valor relativo reside en que proporcionan distintividad estructural a cada una de las composiciones analizadas (ver Tablas 1 a 4 y Figura 3):

Motivos Simples. El número total de figuras animales y humanas incorporadas en las composiciones versus el número total de figuras animales y humanas no incorpo- 


\begin{tabular}{|l|c|c|c|c|}
\hline Localidades & $\begin{array}{c}\text { Motivos } \\
\text { Simples } \\
\text { no compuestos } \\
\text { (Msnc) }\end{array}$ & $\begin{array}{c}\text { Motivos } \\
\text { Simples } \\
\text { Compuestos } \\
\text { (Msc) }\end{array}$ & $\begin{array}{c}\text { Escénica } \\
(\mathrm{Ec})\end{array}$ & $\begin{array}{c}\text { Simétrica } \\
(\mathbf{S m})\end{array}$ \\
\hline Alto Loa & 344 & 104 & 16 & 21 \\
\hline Loa Medio & 45 & 40 & 2 & 6 \\
\hline Loa Inferior & 66 & 49 & 2 & 8 \\
\hline Río Salado & 302 & 364 & 34 & 49 \\
\hline $\begin{array}{l}\text { Salar de } \\
\text { Atacama }\end{array}$ & 136 & 242 & 41 & 17 \\
\hline Taltal & 334 & 1241 & 403 & 13 \\
\hline
\end{tabular}

Tabla 2. Numero de motivos y composiciones observados en cada región.

\begin{tabular}{|l|c|c|}
\hline \multicolumn{1}{|c|}{ Localidades } & Msc/Msnc & Sm/Ec \\
\hline Loa Inferior & 0,74 & 4,00 \\
\hline Loa Medio & 0,89 & 3,00 \\
\hline Alto Loa & 0,30 & 1,31 \\
\hline Rio Salado & 1,21 & 1,44 \\
\hline Salar de Atacama & 1,78 & 0,41 \\
\hline Taltal & 3,72 & 0,03 \\
\hline
\end{tabular}

Tabla 3. Actividad compositiva medida a partir de motivos simples y composiciones. radas en las composiciones. La relevancia de este valor es de primer orden, pues nos permite describir la importancia relativa de la actividad compositiva en cada localidad. Por ejemplo, mientras en Taltal hay 3,4 motivos simples en composición por cada motivo simple no compuesto, en el Loa inferior hay solo 0,74 motivos simples en composición por cada motivo simple no compuesto.

Composición. El número de las composiciones escénicas $(\mathrm{Ec})$ y simétricas $(\mathrm{Sm})$. Arreglos que aparecen durante el Formativo Temprano y Medio con efectos duraderos hasta la época incaica.

Animación. La presencia o ausencia de efectos gráficos de desplazamiento para las figuras en composición, respectivamente: animación y animación nula.7 Conjuntos de atributos de movimiento que son particulares al arte rupestre en las diferentes regiones del Área Centro Sur Andino.

Técnicas. Los tipos de técnicas de diseño consideradas en la construcción de las composiciones: Areales (las unidades son construidas por superficie) y Mixtas, que combinan soluciones areales y lineales (el contorno de la figura es indicado por una línea). Fórmulas que varían ampliamente en términos espaciales y temporales.

Color. Se trata de un material pigmentario cuya conservación diferencial muestra innumerables variaciones tonales, lo cual nos ha obligado a reducir el conjunto a monocromas y policromas (más de un color).

\footnotetext{
7 No se incluyen composiciones exclusivamente geométricas.
}

\begin{tabular}{|l|c|c|c|c|c|c|}
\hline Localidades & Animación & Animación Nula & Areal & Mixta & Monocromo & Policromo \\
\hline Alto Loa & 12 & 25 & 20 & 17 & 36 & 1 \\
\hline Loa Medio & 0 & 8 & 5 & 3 & 4 & 0 \\
\hline Loa Inferior & 0 & 10 & 6 & 64 & 65 & 18 \\
\hline Río Salado & 29 & 54 & 17 & 41 & 37 & 21 \\
\hline Salar de Atacama & 37 & 21 & 409 & 7 & 416 & 0 \\
\hline Taltal & 383 & 33 & & 4 \\
\hline
\end{tabular}

Tabla 4. Variables y estados relativos a los motivos compuestos. 
Un análisis para los estados de la variable Motivos, donde relacionamos Motivos Simples Compuestos (Msc) versus Motivos Simples No Compuestos (Msnc) -un índice que expresa el número de motivos simples compuestos en relación a los simples individuales o en agregadosmuestra que las localidades rupestres se organizan de norte a sur desde menor a mayor actividad compositiva o de composición pictórica. Más aún, lo valores correspondientes a las localidades del río Loa se agrupan en índices inferiores a 1, mientras los restantes lo hacen por arriba de ese mismo índice. Esto sugiere flujos de información visual localizados geográficamente $y$, al mismo tiempo, relativamente excluyentes entre sí. Algo semejante ocurre si examinamos la variable Composición relacionando composiciones $\mathrm{Sm}$ versus Ec, pues los valores de este índice vuelven a organizarse de norte a sur, de mayor a menor simetría a nivel composicional. Un gráfico que relaciona ambos índices nos permite ver las distancias que median entre las diferentes localidades rupestres, distribución que aparece estableciendo una estrecha cercanía entre el Alto Loa y el río Salado (Figura 4). En resumen, los valores relativos a la composición pictórica tienden a agrupar las localidades en norte y sur, sugiriendo un punto de contacto entre estas por las quebradas altas, particularmente por el Alto Loa y río Salado.

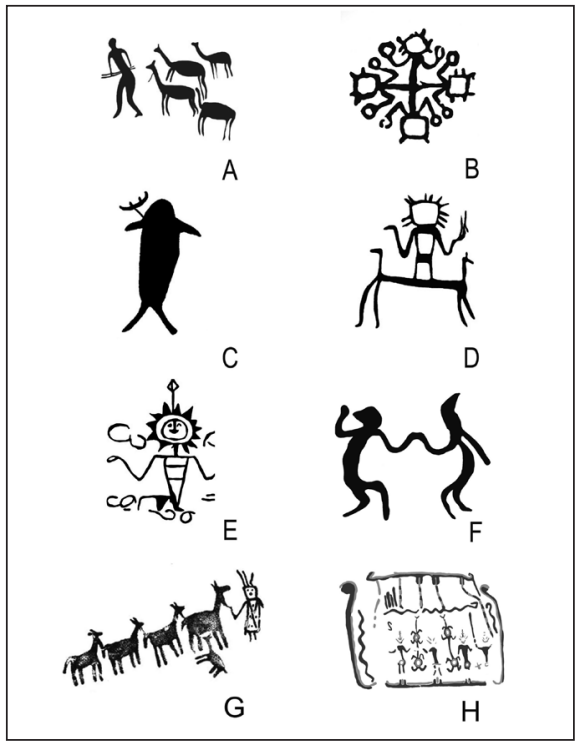

Figura 3. Variables de diseño. A. Composición escénica (Salar de Atacama, Largo: 20,5 cm); B. Composición simétrica (Loa Medio, Largo: $39 \mathrm{~cm}$ ); C. Técnica areal (Taltal, Alto: 35,2 cm); D. Técnica mixta (Alto Loa, Ancho: $150 \mathrm{~cm}$ ); E. Animación ausente (Loa Medio, Alto: $58 \mathrm{~cm}$.); F. Animación presente (Alto Loa, Largo: $27 \mathrm{~cm}$ ); G. Color monocromo (Río Salado, Largo: 49,5 $\mathrm{cm}$ ); H. Color policromo (Río Salado, Largo: $33 \mathrm{~cm}$ ). Todas las composiciones presentan color rojo, con excepción de G (negro) y $\mathrm{H}$ (rojo y verde).

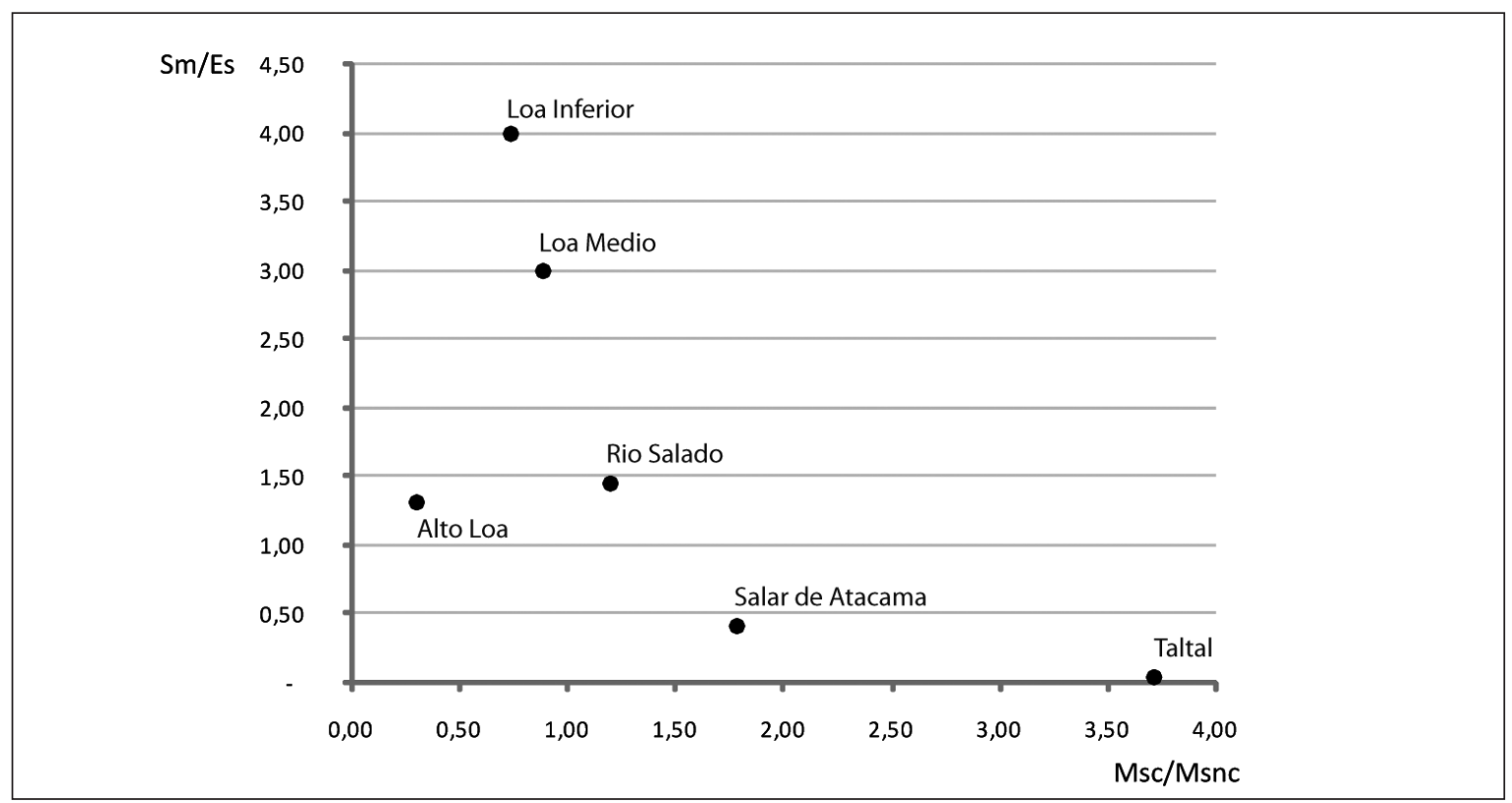

Figura 4. Actividad compositiva. Tipo versus grado. 


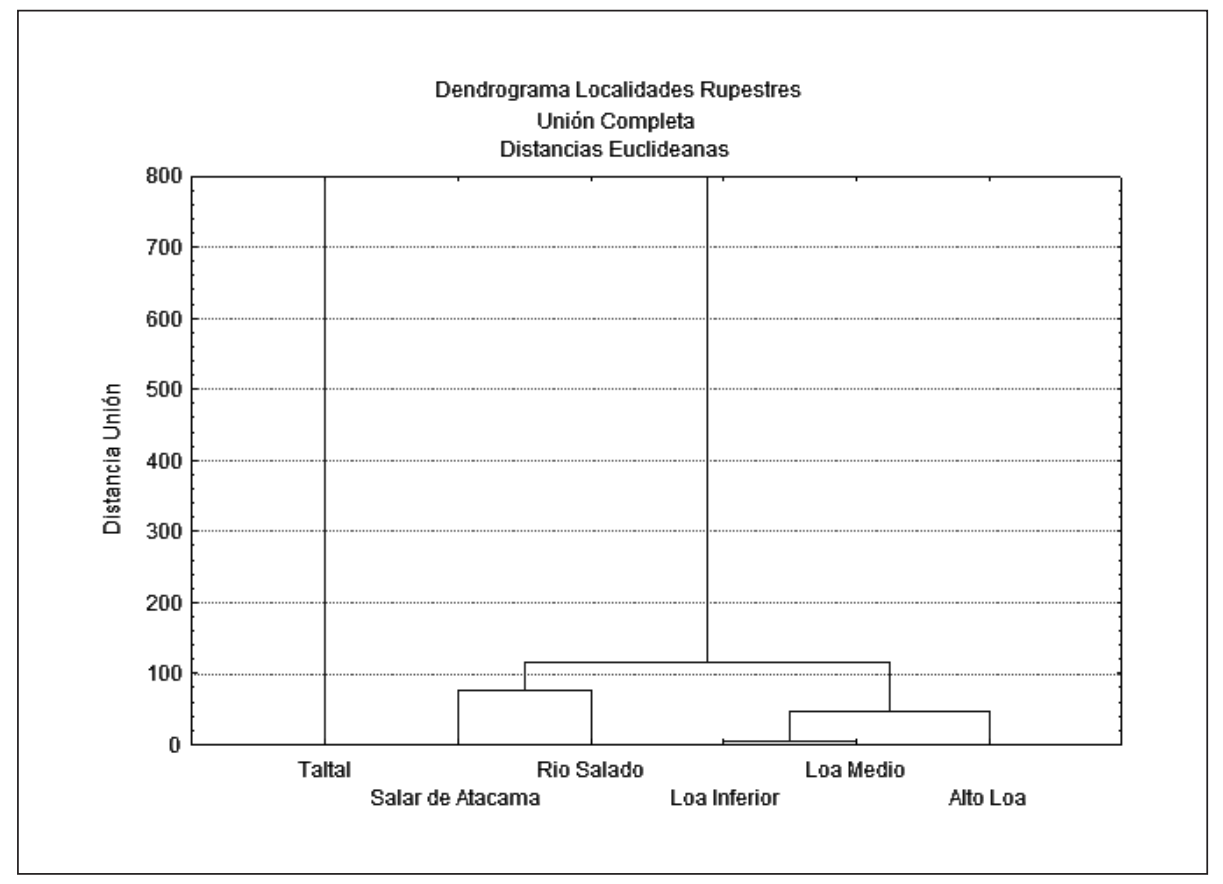

Figura 5. Análisis de Agrupamiento de los estilos de arte rupestre.

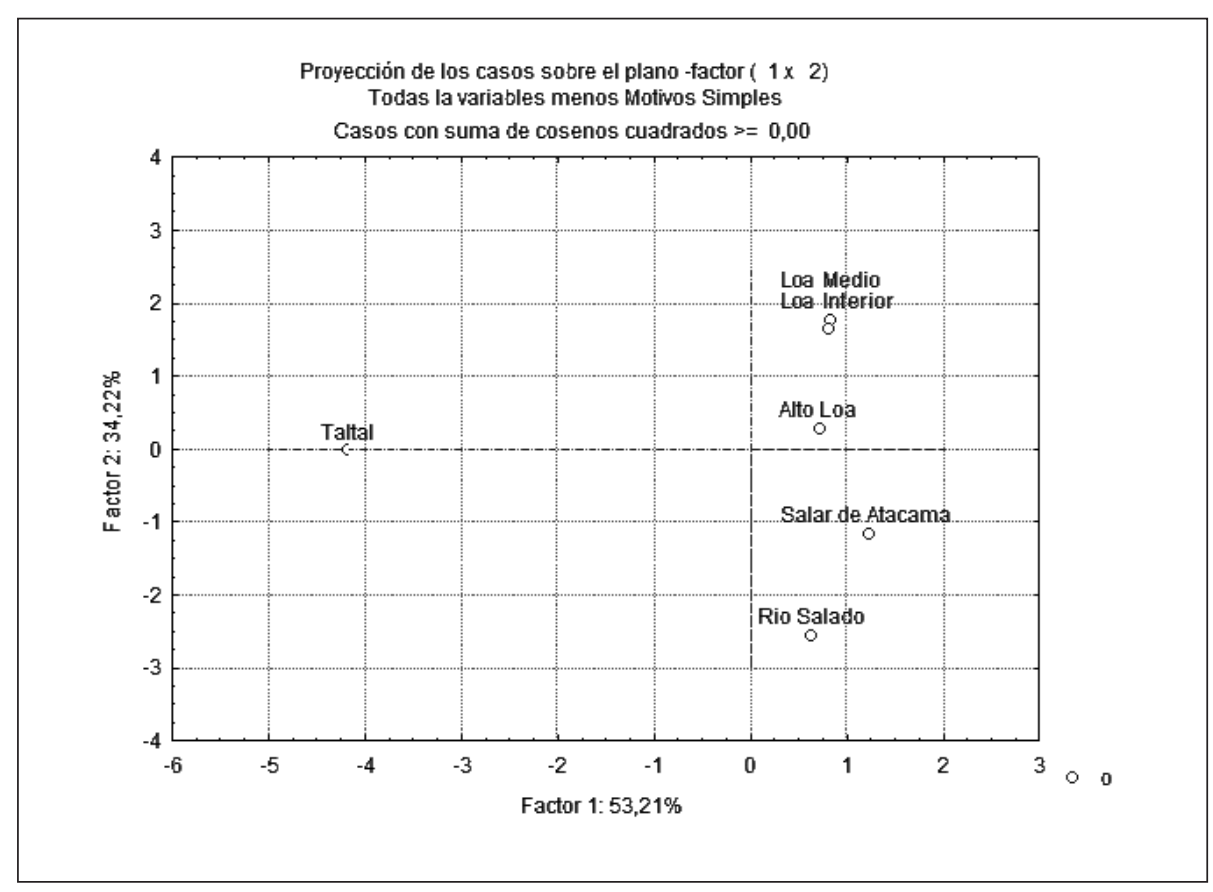

Figura 6. Análisis de Componentes principales de los estilos de arte rupestre. 


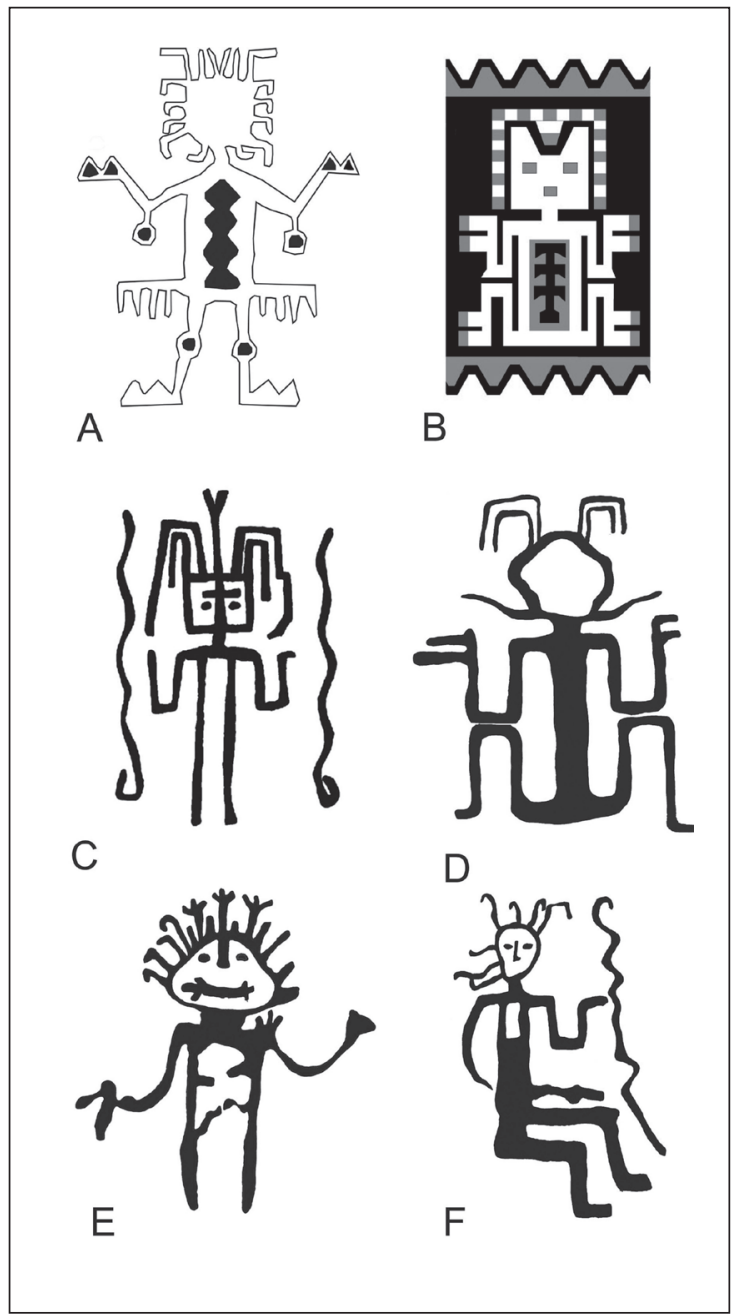

Figura 7. A. Grabado antropomorfo con tocado dentado (Ariquilda, Región de Tarapacá); B. Imagen antropomorfa con apéndices en bolsa textil del cementerio formativo de Pisagua (Región de Tarapacá); C. Antropomorfo con apéndices (Alto Loa, Alto: $120 \mathrm{~cm}$ ); D. Antropomorfo con apéndice (Alto Loa, Alto: $500 \mathrm{~cm}$ ); E. Antropomorfo con apéndices e incisivos (Loa Medio, Alto: $29 \mathrm{~cm}$ ); F. Antropomorfo con apéndices (Loa Medio, Alto: $46 \mathrm{~cm}$ ). Las pinturas rupestres ( $\mathrm{C} \mathrm{a} \mathrm{F})$ son de color rojo.

Ante estas sugerentes variaciones en el eje geográfico norte/sur, tomamos las variables de orden pictórico (B a E) y las sometimos a dos distintas técnicas de tipo exploratorio y clasificatorio: Análisis de Agrupamiento y Análisis de Componentes Principales. El resultado del Análisis de Agrupamiento, que se efectuó utilizando como medida de la diferencia la Distancia Euclidiana y una técnica de Unión Completa, mostró que, bajo 120 unidades, se producen dos claros grupos: uno formado por las localidades del río Loa y otro por el río Salado y el salar de Atacama (Figura 5). Taltal no participa de esta distribución, siendo desde el punto de vista estadístico completamente diferente. El análisis de Componentes Principales, que resume la mayor parte de la información contenida por las variables originales en los dos primeros ejes (componentes principales) del gráfico, fue coincidente con las anteriores apreciaciones estadísticas (Figura 6). A la luz de estos resultados, podemos concluir provisoriamente que esta distribución de flujos de información visual ofrecen un proxy de los vínculos histórico sociales entre las localidades durante la prehistoria del desierto de Atacama. En tal sentido, es relativamente claro que, a nivel estructural, las comunidades del río Loa comparten lógicas composicionales semejantes, códigos que no comparten con el río Salado y las quebradas precordilleranas del salar de Atacama, cuyo arte presenta grandes afinidades entre sí. No ocurre lo mismo con aquellas pinturas en sitios de la costa de Taltal, pues es el conjunto pictórico que presenta mayores diferencias. Estas semejanzas y diferencias estadísticas adquieren mayor valor cultural si analizamos los conjuntos de pinturas rupestres desde un punto de vista iconográfico, enfoque formal que muestra importantes relaciones de afinidad entre las localidades, aunque siempre dentro de claras autonomías relativas.

\section{* Localidades rupestres y Circulación ICONOGRÁFICA}

\section{Alto Loa}

Predominan aquí las figuras en posición frontal, con tocado dentado y objetos en las manos (Figura 7). Esta es una iconografía característica de la región de Tarapacá (al norte del río Loa), donde es particularmente numerosa en sitios con grabados como Tamentica, Ariquilda y Suca (Chacama y Espinosa 2005; Mostny y Niemeyer 1983; Sepúlveda et al. 2005). Se trata de una imagen que excede el ámbito rupestre, pues aparece en tejidos y otros objetos del período Formativo Temprano. Otro ícono clave de origen tarapaqueño es la figura de un ave con sus alas extendidas (Formativo Temprano/Intermedio Tardío), que aparece con frecuencia en los sitios mencionados y que en el Alto Loa fue representado en pinturas y grabados 


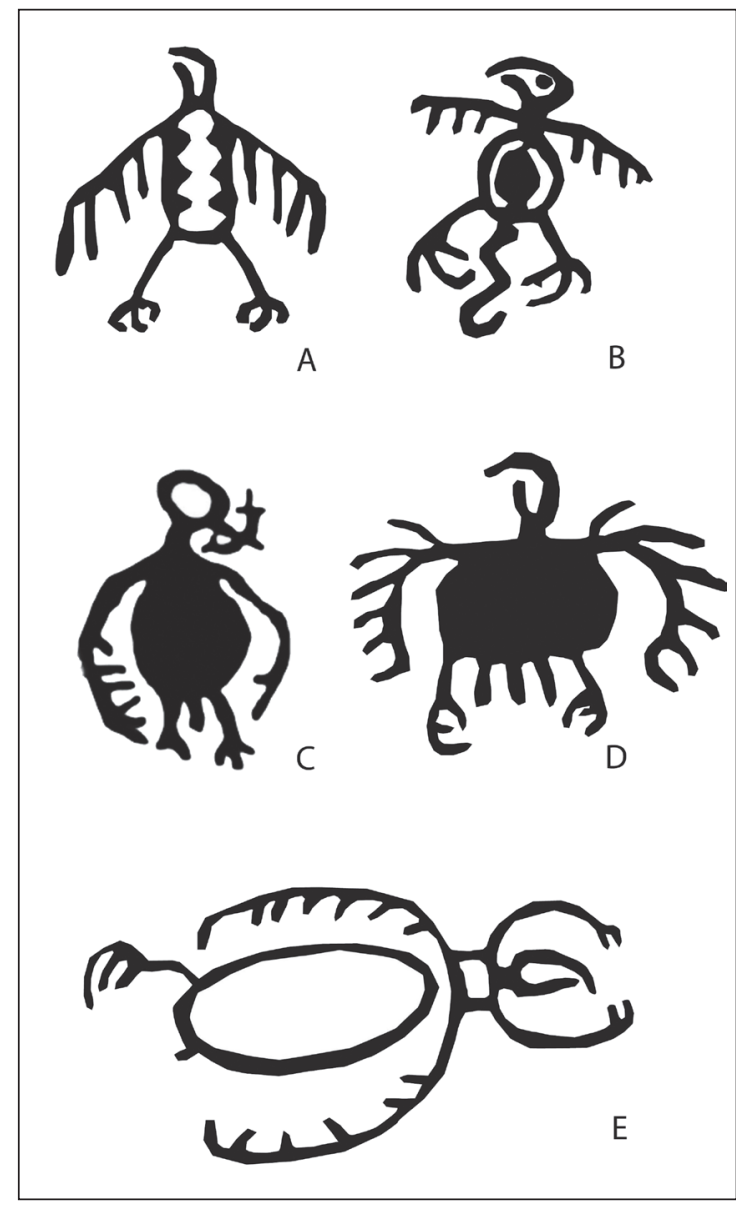

Figura 8. A. Grabado de ave emplumada (Ariquilda, Región de Tarapacá); B. Grabado de ave emplumada (Tamentica, Región de Tarapacá); C. Pintura de ave emplumada (Alto Loa, Alto: $38 \mathrm{~cm}$ ); D. Grabado de ave emplumada (Alto Loa, Largo: $140 \mathrm{~cm}$ ); E. Pintura de ave emplumada (Alto Loa, Largo: $254 \mathrm{~cm}$ ). Todas las pinturas son de color rojo.

(Figura 8). Estas distribuciones y redundancias con este arte son aún más amplias, pues en esta localidad no faltan las figuras antropomorfas enfrentadas con numerosos efectos de movimiento, simios de cola larga, volutas que nacen de una recta, camélidos de cuerpo rectangular y personajes ataviados con túnicas trapezoidales (todos del Intermedio Tardío) y una figura rectangular decorada con iconografía textil formativa "Alto Ramírez" (Formativo Medio) (p.e., Berenguer 1999; Briones y Chacama 1987; Cáceres y Berenguer 1996; Mostny y Niemeyer 1983; Núñez 1985; Núñez y Briones 1967-68; Pimentel y Montt 2008; Vilches y Cabello 2011; Tolosa 1967). En

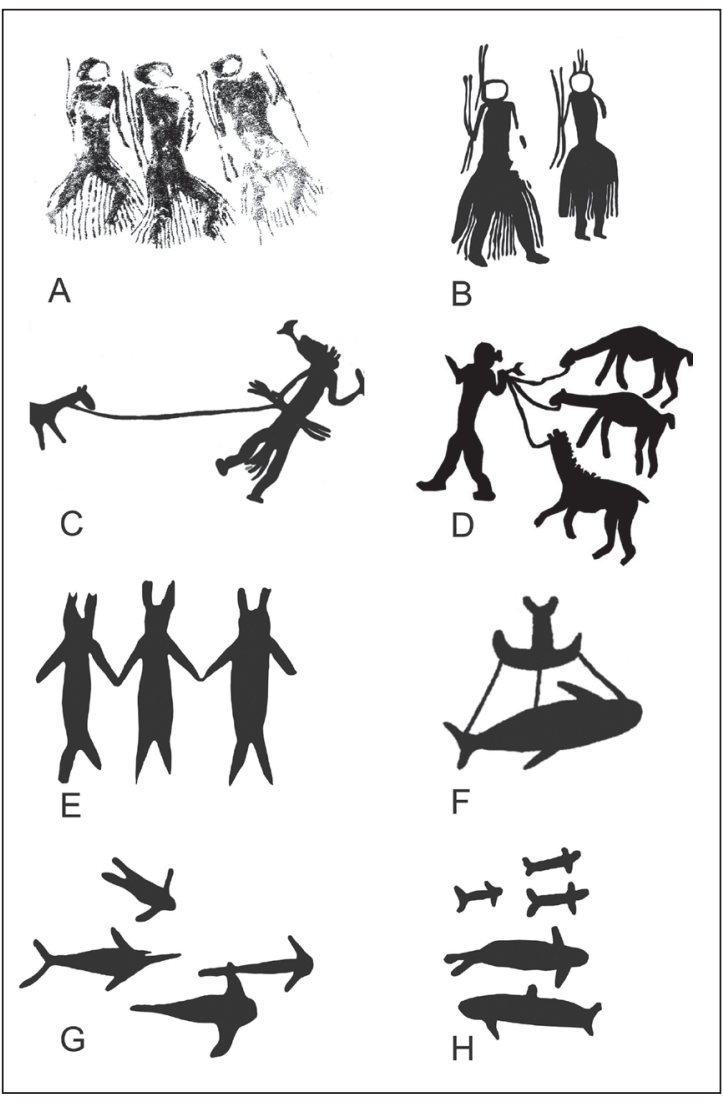

Figura 9. A. Cazadores con faldellines, propulsores y dardos (Río Salado, Alto: $18 \mathrm{~cm}$ ); B. Cazadores con faldellines, propulsores y dardos (Salar de Atacama, Alto: $30 \mathrm{~cm}$ ); C. Cazador arreando camélido (Río Salado, Largo: $38 \mathrm{~cm}$ ); D. Cazador arreando camélidos (Salar de Atacama, Alto: $30 \mathrm{~cm}$ );

E. Personajes con tocado biapendicular (Loa Inferior, Alto: 20,5 $\mathrm{cm}$ ); F. Personaje con tocado biapendicular (Taltal, Alto: $23 \mathrm{~cm}$ ); G. Fauna marina (Loa Inferior, Largo: $28 \mathrm{~cm}$ ); H. Fauna marina (Taltal, Alto: $21 \mathrm{~cm}$ ). Todas las pinturas son de color rojo.

este mismo sentido, hay que destacar una última semejanza de orden técnico, pues el tamaño de muchas figuras excede el metro de altura, alcanzando valores superiores a los $4 \mathrm{~m}$, un tipo de monumentalidad que solo es comparable con los geoglifos o el land art tarapaqueño: grandes figuras confeccionadas sobre laderas de cerros y planicies desérticas que se alinean junto a los antiguos caminos de esa región (Briones 2008; Cerda et al. 1985; Núñez 1976).

Dadas las evidencias y la particular distancia estadística de esta localidad respecto a las otras en estudio, es clara su estrecha conexión con las poblaciones de Tarapacá, se- 
guramente vía Guatacondo desde el sector de Collahuasi (ver Figura 1). Sin embargo, este vínculo no clausuró su autonomía simbólica y social, pues en ella hay predominio de la pintura sobre otras técnicas tarapaqueñas, proceso que, mirado desde la perspectiva de la sucesión de estilos conocidos, debió comenzar en momentos posteriores al período Arcaico.

\section{Loa Medio}

Los sitios al oriente y poniente de Calama presentan una importante variedad de motivos, con soluciones formales que hacen de este conjunto el resultado de una expresión particularmente local. Estos dispositivos afectan de manera diferente a dos grupos cuyas iconografías se ajustan en lo general a los temas que caracterizan los modos visuales formativos y aquellos posteriores al $800 \mathrm{DC}$ de la región. Los primeros suelen aludir a la figura con tocado radial y objetos en sus manos, frecuente en la región de Tarapacá, pero con arreglos menos usuales, que los representan sentados, de perfil y con tocados de triángulos dispuestos radialmente o pequeños trazos que cruzan sus labios, elementos que han sido interpretados como colmillos entrecruzados o espinas (Mostny y Niemeyer 1983; Núñez 1984b) (ver Figura 7). Sus fórmulas de diseño también son inusuales, pues están confeccionados mediante trazos de superficie restringida que recuerdan la técnica del grabado. Cabe notar aquí las semejanzas iconográficas entre estas pinturas y lo grabados de Lasana, donde las pinturas son escasas (Rojas 2005). Los segundos motivos suelen portar túnicas y tocados semilunares que aluden también al arte tarapaqueño, no obstante mucha de la indumentaria difiere de la conocida para el norte grande chileno, pues sugiere la presencia de un camisón que cubre un tejido dispuesto como falda o un angostamiento de la túnica poco más arriba de las rodillas. Esa modalidad de vestuario también fue representada en el extremo proximal de una cuchara de madera obtenida por Sénéchal de la Grange en el cementerio Dupont o Chunchuri (post 900 DC) en la afueras de la ciudad de Calama (Boman 1908, fig. 173).

Al igual que en el Alto Loa, las vinculaciones iconográficas se extienden hacia la región de Tarapacá. Sin embargo, aquí se aprecia un componente local que proporciona a esta localidad una autonomía simbólica y social especialmente notoria respecto a otras del interior del desier- to de Atacama. Las principales vías de comunicación con el norte, rutas troperas de gran magnitud y extensos sitios cubiertos por el land art tarapaqueño, provienen efectivamente desde la localidad de Quillagua en el río Loa inferior, que sabemos operó como frontera interregional desde épocas postarcaicas (Agüero et al. 2006; Agüero y Cases 2004; Gallardo et al. 1993; Latcham 1933; Pimentel y Montt 2008) (ver Figura 1).

\section{Loa Inferior}

Quebrada Amarga, un afluente del río Loa a $30 \mathrm{~km}$ de su desembocadura, es una localidad de tránsito entre la costa y el interior, extraordinaria por su arte rupestre vinculado a las poblaciones costeras del desierto de Atacama (Artigas y García 2010). Hay aquí pinturas y grabados que representan albacoras, mantas raya y otros animales marinos, así como rebaños de camélidos y también personajes con tocados de doble trazo divergentes que coronan sus cabezas (Figura 9). Por ahora, conocemos pocos sitios rupestres costeros, pero los atributos de las figuras en Quebrada Amarga -tocados cefálicos, fauna marina y terrestre- son los mismos que aquellos registrados en la costa de Taltal (p.e., Niemeyer 2010). A primera vista, sus semejanzas son concluyentes, pero faltan aquí elementos visuales significativos como los temas compositivos: no hay escenas de arrastre de grandes presas mediantes embarcaciones tripuladas, ni tampoco caza de camélidos con arco y flecha. Algo semejante ocurre con la tecnología, pues en Quebrada Amarga se utiliza el grabado y el pictograbado, formas de producción ausentes en Taltal. Además, existen otras iconografías (batracios, círculos y figuras geométricas reticuladas), que son exclusivas del arte rupestre tarapaqueño y aquellas de las cerámicas San Miguel y Pocoma-Gentilar (Intermedio Tardío) (p.e., Niemeyer y Schiappacasse 1991; Uribe 1999). Estos elementos sitúan a esta localidad en un dominio de autonomía relativa, a pesar de su posición geográfica en la ruta que conecta directamente la costa con la localidad de Guatacondo (ver Figura 1).

\section{Taltal}

La costa de Taltal se emplaza a unos $400 \mathrm{~km}$ al sur del río Loa y a $300 \mathrm{~km}$ al suroeste del salar de Atacama, siendo la localidad rupestre más austral del desierto de Atacama. La mayor concentración de pinturas fue ejecutada en El Médano, una quebrada entre las altas cumbres de la cor- 
dillera que se eleva junto al litoral (Mostny y Niemeyer 1984; Niemeyer 2010; Núñez y Contreras 2006). Las obras rupestres son numerosas pero el tema recurrente es una balsa tripulada por uno o dos individuos que arrastra grandes presas como ballenas, tortugas, delfines y lobos marinos (ver Figura 9). También son frecuentes las escenas de caza de guanacos mediante el uso de arco y flecha y grupos de animales marinos en desplazamiento. Las pinturas no se restringen a este sitio, en especial estos últimos diseños, pues han sido hallados al interior de estrechos aleros de piedra en el sector litoral, donde se llevaron a cabo actividades de desconche y faenamiento de peces. Sin embargo, ninguna de las obras conocidas hace referencia a los temas de caza tan populares en El Médano.

La evidencia de interacción social con el norte de la región y el salar de Atacama es bien conocida en la literatura arqueológica (Castelleti 2007; Núñez 1984a). Dichas relaciones comenzaron hacia el período Arcaico Tardío (Ballester y Gallardo 2011; Gallardo 2009b) y debieron llevarse a cabo vía marítima y mediante un sendero que conecta esta localidad con el sur del salar de Atacama (p.e., Bittman 1979; Philippi 1860) (ver Figura 1). La iconografía marina aparece también en el sitio Gatico al norte de Cobija y en aquellos de Quebrada Amarga (Artigas y García 2010; Hornkohl 1954-55). Sin embargo, no comparte con estos la estructura ni la forma de los diseños. Las escenas en la pintura de Taltal son exclusivas de esta localidad, así como la delicada factura de muchas de sus figuras zoomorfas. Respecto a su relación con el Salar, solo es posible sugerir una de tipo estructural a nivel compositivo, pues el arrastre de múltiples presas marinas es curiosamente semejante al pastor que conduce su rebaño en las pinturas más tempranas del interior del desierto de Atacama. Desde el punto de vista rupestre, la autonomía de las poblaciones de cazadores recolectores costeros es probablemente la mayor del grupo de localidades de este estudio.

\section{Río Salado}

La localidad de Río Salado se sitúa sobre los 3.000 m.s.n.m. y su cuenca es el principal afluente del río Loa, con varios cursos de agua dulce como los ríos Cupo, Toconce, Hojalar y Caspana y extensas áreas de pastizales en Turi, Linzor e Inacalari. Las áreas con potencial agrícola y mantención de fauna silvestre y domesticada permitieron una ocupación continua y permanente desde el Arcaico Temprano (Aldunate et al. 1986; De Souza 2004; Sinclaire 2004; Uribe y Adán 2004). La mayoría de los sitios se emplaza junto a los ríos y en abrigos rocosos o pared de quebrada protegida por una cornisa. Son abundantes las imágenes naturalistas del estilo Confluencia, que representan cazadores con propulsores y dardos - en ocasiones vestidos con faldellines de pabilos y tocados en sus cabezas- asociados a gráciles camélidos silvestres, en actitud de caza y arreo (Gallardo y De Souza 2008; Gallardo y Yacobaccio 2005) (ver Figura 9). Menos numerosos son las composiciones Cueva Blanca (Formativo Medio) que organizan figuras geométricas, antropomorfos y zoomorfos en arreglos simétricos y policromos, cuyo origen se relaciona con la iconografía tarapaqueña presente en tapices que se distribuyen hasta el Loa Medio (Sinclaire 1999). Más abundantes son las pinturas del período Intermedio Tardío, agrupadas en tres modalidades. Estas se definen esencialmente por figuras antropomorfas y zoomorfas con escasos geométricos de tamaño reducido. En su mayoría conforman pequeñas escenas de antropomorfos representados de frente y alineados unos al lado de los otros o un antropomorfo que lleva atado un camélido. En otros casos, se trata de paneles conformados por múltiples figuras agregadas sin orden claro aparente. Además, se reconocen escenas de posibles caravanas con figuras pintadas de camélidos con rasgos más ortogonales, que evidenciarían la transición estilística hacia el período Tardío (Sepúlveda 2011). Finalmente, también se registran para las etapas finales de la prehistoria, aunque numéricamente mejor representados en la técnica del grabado, los estilos Quebrada Seca con sus camélidos de trazo restringido y estructura ortogonal y Santa Bárbara, con personajes vestidos con camisas rectangulares arreando animales de cuerpo rectangular (Sepúlveda 2004, 2008; Vilches y Uribe 1999).

Los estilos formativos tempranos - por recurrencia, estructura e iconografía - sugieren una estrecha integración sociocultural con las poblaciones del Salar, una distribución que no comparte con el Alto Loa, donde son escasas las imágenes Confluencia y pocos los sitios del estilo Taira Tulan. Algo distinto ocurre con las obras del estilo Cueva Blanca, que son relativamente numerosas en el Salado, pero menos frecuentes en otras localidades, que podría tratarse de un aporte local al imaginario visual de la región. En relación a los estilos más tardíos, la iconografía pictórica muestra algunas coincidencias con localidades 
vecinas, pero en lo general hay un desarrollo dominado por la retoma gráfica de obras visuales más tempranas.

El río Salado tiene una historia jalonada por vínculos extra locales desde el período Formativo Temprano (1500 - 500 AC) en adelante. Sin embargo, las evidencias tienden a mostrar relaciones preferenciales con el altiplano de Bolivia inmediato y el salar de Atacama, evidenciadas tanto por el asentamiento, como por el flujo de cerámicas y materias primas líticas realizados por senderos longitudinales sobre los 3.000 m.s.n.m. (p.e., Aldunate y Castro 1981; Castro et al. 1992; Rees y De Souza 2004; Martínez 1985b) (ver Figura 1).

\section{Salar de Atacama}

El salar de Atacama limita al oriente con un macizo precordillerano que nace en la Puna Salada, sobre los 4.000 m.s.n.m. Numerosas son las quebradas que descienden desde este lugar y muchas tienen agua dulce permanente asociadas a pastizales, áreas de caza y zonas aptas para la agricultura. Esto favoreció un asentamiento prehistórico desde por lo menos el $8000 \mathrm{AC}$ y las pinturas rupestres tienden a concentrarse en refugios de pequeña cobertura o paredones rocosos protegidos. En la mayoría de los sitios, está presente el estilo Confluencia, con una menor intrusión de composiciones del estilo Cueva Blanca e iconografía relativa a los estilos Santa Bárbara y Quebrada Seca (Gallardo 2009b; Núñez et al. 1997; Núñez et al. 2009; Sepúlveda 2004, 2008).

La distribución de los tipos cerámicos San Pedro sugiere una amplia red de interacción que afecta a todas las localidades rupestres en estudio, en especial desde el Formativo Tardío (100 - 400 DC) (p.e., Núñez y Dillehay 1995; Llagostera 1996; Uribe 2006). No obstante, los actuales conocimientos arqueológicos son pobres para generar expectativas relacionadas con la estrecha distancia estadística que la une con la localidad rupestre del Río Salado, aunque no parece desafortunado pensar que su valor pudo estar relacionado con su acceso ventajoso hacia el altiplano. Por ahora, solo poseemos dos datos correlativos para esta interacción: el primero está relacionado con la circulación de basalto vítreo - cuya fuentes se hallan en el río Salado- hacia las quebradas altas del oasis de San Pedro de Atacama; y el segundo, a la presencia masiva de grabados Taira Tulan y Quebrada Seca que son estilos de gran abundancia en las quebradas del Salar (Gallardo 2009b; Seelenfreund et al. 2004). Así, pese a compartir ciertos procesos en determinados momentos, estas comunidades mantuvieron una autonomía relativa, pues es claro que desarrollaron una cultura que tuvo efectos a nivel interregional, posición privilegiada por su interacción con el Noroeste Argentino desde el período Arcaico Tardío en adelante (Llagostera 2004; Gallardo 2009b; Núñez et al. 2007; Sepúlveda 2002; Yacobaccio 2004).

\section{* Conclusiones}

Cuando Ricardo Latcham publicó La arqueología de la región atacameña en 1938 , tenía pocas dudas de que esta área cultural era resultado de un tipo de integración diferente a otras por él estudiadas. Sin embargo, carecía de los modelos adecuados para percibir los procesos de construcción identitarios producto de la historia local, las interacciones preferenciales entre estas comunidades y aquellas vecinas fuera de la región. La investigación reciente ha acreditado de facto este proceso, pues ahora es incuestionable que la geopolítica de los emplazamientos permitió crear flujos más directos y estables como aquellos verificados entre el salar y el Noreste Argentino, el río Salado y el altiplano boliviano y el Loa Inferior con los oasis tarapaqueños (p.e., Agüero et al. 1997; Aldunate y Castro 1981; Núñez et al. 2007). Por ahora, los avances sobre la estructura interna de las relaciones intercomunales del desierto de Atacama permanecen en una etapa seminal. Los resultados de Tarragó (1984), a partir de la cerámica, son en muchos aspectos solidarios con aquellos detectados en este estudio rupestre, en especial aquel que la autora llama "callejón de interacción" que uniría el río Salado con el salar de Atacama y a estos, con el Noroeste Argentino.

A modo de conclusión preliminar, hay que considerar que los flujos diferenciales de los distintos sistemas visuales pictóricos tienen su origen durante el período Formativo Temprano, época cuando se da comienzo al sistema de comunidades con territorios limitados por ecozonas y posicionamientos geográficos específicos. Esto debió establecer una base social para la interacción, que de acuerdo a la localización y la constitución comunal estableció un sistema de relaciones preferenciales. Un patrón de interacción que se ajusta al análisis de pinturas rupestres. El Alto Loa pudo estrechar sus vínculos con Guatacondo 
vía Miño-Collahuasi y el río Salado con el altiplano boliviano y las comunidades del Salar, en un movimiento horizontal que une las cabeceras de quebradas precordilleranas. El Loa Medio estableció estrechas relaciones con las localidades de Quillagua y Guatacondo, como lo muestran de manera incuestionable los senderos troperos. El Loa inferior y sus contingentes costeros aparecen articulados con las mismas localidades, las vías de comunicación son claras al respecto. Más problemático resulta determinar las interacciones propiamente costeras, en particular cuando sabemos que las prospecciones y registros rupestres no han sido sistemáticos. Sin embargo, las diferencias estructurales entre el Loa Inferior y Taltal sugieren poblaciones con identidades propias, lo que es consecuente con los modos visuales presentes en Taltal, que por estructura está más vinculado a las comunidades del sur del salar de Atacama.

Un análisis preliminar de caracterización físico-química elemental en muestras de pigmentos procedentes de cinco de las localidades en estudio, proporcionó información complementaria. Con este procedimiento se identificó el tipo de mezcla empleada en cada pintura considerando tres criterios: a) la distribución homogénea o heterogénea de los elementos presentes en las mezclas; b) la morfología y c) el tamaño de los elementos inorgánicos al origen del color, en particular de los óxidos de hierro. Los resultados indican la presencia de: 1) mezclas naturales con poco óxido de hierro, 2) mezclas naturales con mucho óxido de hierro, 3) mezclas intencionales con arcillas y óxidos de hierro agregados y 4) mezclas constituidas esencialmente por óxidos de hierro. De esta forma, se concluye que las mezclas para la obtención de la pintura roja son muy semejantes para el río Salado y el salar de Atacama, distintas a las del sector de Taltal y Quebrada Amarga, segregándose completamente las del Alto Loa (Tabla 5). Estas diferencias están probablemente relacionadas con el acceso a fuentes locales y el manejo de tecnologías distintivas que confirman las autonomías relativas expresadas por nuestro análisis visual a nivel iconográfico (Sepúlveda 2012).

Esta estructura intrarregional produjo una zona de impermeabilidad relativa que separó a las poblaciones del Loa de aquellas en el Salado y el Salar, y a éstas de las que habitaban la costa desértica. Difícilmente podríamos sostener que entre todas ellas no hubo interacción social. Lo que nuestro estudio afirma es que cada localidad tiene una historia particular dentro de lo general y que fue precisamente esto lo que determinó la naturaleza específica de sus tejidos vinculares. Pero, quizás el dato correlativo más importante sobre estos flujos de información visual es que, en tanto el arte rupestre es un artefacto inmueble, el conocimiento adquirido pudo estar más relacionado con la circulación de personas que con los bienes.

Aunque nuestros resultados permanecen dentro del campo de la cultura visual, pensamos que aportan a la construcción de modelos productivos, puesto que, al considerar otros registros de cultura material, permitirán dilucidar las dinámicas concretas de las tramas de interacción social. $\mathrm{Si}$, como creemos, el arte rupestre sirvió como expresión identitaria de las distintas comunidades del desierto de Atacama y sus relaciones, entonces estamos frente a una apertura de nuevas líneas de investigación acerca de sus estructuras, cambios y rearticulaciones en el dominio de la historia y agencia social.

Agradecimientos Estamos en especial deuda con los investigadores de las localidades atacameñas incluidas en este estudio de carácter regional, quienes generosamente nos permitieron el registro de arte rupestre. Comprometen nuestra gratitud de norte a sur; José Berenguer, Agustín Llagostera, Lautaro Núñez, Francisca Fernández, Mario Vázquez, Calógero Santoro, Daniela Valenzuela, Hans Niemeyer, José Castelleti, Patricio Núñez y Rodolfo Contreras. Los resultados de este proyecto no habrían sido posibles sin la colaboración del equipo en terreno, laboratorio y sus ideas: Bárbara Cases, Mariana Ugarte, Benjamín Ballester, Charles Rees, Carole Sinclaire, Alex San Francisco, Jose Castelleti, Nicole Fuenzalida, Wilfredo Faúndez, Miguel Saavedra, Lorena Arancibia, Rodrigo Lorca, Francisco Rivera, Liliana Bueno, Ignacio Torres, Magdalena de la Maza, Julieta Elizaga, Leslia Véliz, Ángela Guajardo, Marco Arenas, Anahí Ré, Mariela Pino, Cristián Solar, José Blanco, María Paz Casanova, Francisca Gili, Valeria Sepúlveda, Manuel Alarcón, Iván Maureira, Bernardita Brancoli, Isabel Christie, Daniela Ahumada, Paulina Riquelme, Paulina Arenas, Lorena Avello, Ignacio Helmke, y nuestro operador en Taltal, Pedro Mercado. Agradecemos también a Christina Torres-Rouff por sus correcciones al inglés. Finalmente, nuestros reconocimientos a las comunidades atacameñas y al Fondo Nacional de Ciencia y Tecnología (Proyecto FONDECYT 1070083). 


\section{* Referencias citadas}

AGÜERO, C., M. URIBE, P. AYALA y B. CASES, 1997. Variabilidad textil durante el período Intermedio Tardío en el valle de Quillagua: una aproximación a la etnicidad. Estudios Atacameños 14: 263-290.

AGÜERO, C., y B. CASES, 2004. Quillagua y los textiles formativos del Norte Grande de Chile. Chungara 36 (número especial 2): $599-618$.

AGÜERO, C., AYAlA. P., URIBE, M., CARRASCO, C. y B. CASES, 2006. El período formativo desde Quillagua, Loa inferior (norte de Chile). En Esferas de interacción prehistóricas y fronteras nacionales modernas: Los Andes sur centrales, H. Lechman (Ed.), pp. 73-118. Instituto de Estudios Peruanos, Lima.

ALDUNATE, C., y V. CASTRO, 1981. Las Chullpas de Toconce y su relación con el poblamiento altiplánico en el Loa Superior: Período Tardío. Editorial Kultrún, Santiago.

ALDUNATE, C., J. BERENGUER, V. CASTRO, L. CORNEJO, J. L. MARTÍNEZ y C. SINCLAIRE, 1986. Cronología y asentamiento en el región del Loa Superior. Dirección de Investigación y Bibliotecas de la Universidad de Chile, Santiago.

ARTIGAS, D., yJ. GARCÍA, 2010. Quebrada Amarga: El encuentro de albacoras y llamas. Global Rock Art. Anais do Congresso Internacional de Arte Rupestre IFRAO (Fundhamentos IX) 4: 1365-1380.

BALLESTER, B., y F. GALLARDO, 2011. Prehistoric and Historic networks on the Atacama desert coast (northern Chile). Antiquity 85 (329): 875-889.

BERENGUER, J., 1999. El evanescente lenguaje del arte rupestre en los Andes atacameños. En Arte rupestre en los Andes de Capricornio, J. Berenguer y F. Gallardo (Eds.), pp. 57-96. Museo Chileno de Arte Precolombino, Santiago.

2004a. Cinco milenios de arte rupestre en los Andes atacameños: Imágenes para los humano, imágenes para lo divino. Boletín del Museo Chileno de Arte Precolombino 9: 75-108.

2004b. Tráfico de caravanas, interacción interregional y cambio cultural en la Prehistoria Tardía del Desierto de Atacama. Ed. Sirawi, Santiago.

BITTMAN, B., 1979. Cobija y alrededores en la época colonial. $A c-$ tas del VII Congreso de Arqueología de Chile: Altos de Vilches (1977): 327-56.

BOMAN, E., 1908. Antiquités de la región andine de la république argentine et du désertd'atacama. Tome second. Imprimerie Nationale, Paris.
BRIONES, L., 2008. Geoglifos del norte de Chile. Región de Arica y Parinacota. Consejo de Monumentos Nacionales, Santiago.

BRIONES, L., y J. CHACAMA, 1987. Arte rupestre de Ariquilda: Análisis descriptivo de un sitio con geoglifos y su vinculación con la prehistoria regional. Chungara 18: 15-66.

CÁCERES, I., y J. BERENGUER, 1996. El caserío de Santa Bárbara, su relación con la W'aka de Taira, Alto Loa. Chungara 28 $(1-2): 381-393$.

CASES, B., C. REES, G. PIMENTEL, R. LABARCA y D. LEIVA, 2008. Sugerencias desde un contexto funerario en un "espacio vacío" del desierto de Atacama. Boletín del Museo Chileno de Arte Precolombino 13 (1): 51-70.

CASTELLETI, J., 2007. Patrón de asentamiento y uso de recursos a través de la secuencia ocupacional prehispana en la costa de Taltal. Tesis de magíster. Universidades de Tarapacá y Católica del Norte, Arica.

CASTRO, V., C. ALDUNATE, J. BERENGUER, L. CORNEJO, C. SINCLAIRE y V. VARELA, 1992. Relaciones entre el noroeste argentino y el norte de Chile: el sitio O2-Tu-002, Vegas de Turi. En Taller: De Costa a Selva: Producción e Intercambio entre los Pueblos Agroalfareros de los Andes Centro-Sur, pp. 215-239. Instituto Interdisciplinario de Tilcara/ Universidad de Buenos Aires, Tilcara.

CERDA, P., S. FERNÁNDEZ y J. ESTAY, 1985. Prospección de geoglifos de la provincia de Iquique, primera región Tarapacá, Norte de Chile: Informe preliminar. En Estudios de Arte Rupestre, C. Aldunate, J. Berenguer y V. Castro (Eds.), pp. 331-348. Museo Chileno de Arte Precolombino, Santiago.

CHACAMA, J., y G. ESPINOSA, 2005 [1999]. La Ruta de Tarapacá: Análisis de un mito y una imagen rupestre en el Norte de Chile. En Rupestreweb, http: //rupestreweb.info/tarapaca. html

DE BOER, W., y J. MOORE, 1982. The measurement and meaning of stylistic diversity. Nawpa Pacha 20: 147-162.

DE BOER, W., 1990. Interaction, imitation, and communication as expressed in style: The Ucayali experience. En The uses of style in art history, M. Conkey y C. Hastorf (Eds.), pp. 82-104. Cambridge University Press, Cambridge.

DE SOUZA, P., 2004. Cazadores recolectores del Arcaico Temprano y Medio en la cuenca superior del río Loa: Sitios, conjuntos líticos y sistemas de asentamientos. Estudios Atacameños 27: 7-42. 
DE SOUZA, P., CARTAJENA, I., NÚÑEZ, L. y C. CARRASCO, 2007. Cazadores-recolectores del Arcaico Tardío y desarrollo de complejidad social en la Puna de Atacama: Las evidencias del sitio Tulán-52 (Norte árido de Chile). I Jornadas Nacionales de Arqueología de Cazadores Recolectores, 28 al 30 de noviembre de 2007, Universidad Internacional SEK, Santiago.

FRIEDRICH, M., 1970. Design structure and social interaction: Archaeological implications of an ethnographic analysis. AmericanAntiquity 35 (3): 332-343.

2001. Arte rupestre y emplazamiento durante el Formativo Temprano en la cuenca del río salado (Desierto de Atacama, norte de Chile). Boletín del Museo Chileno de Arte Precolombino 8: 81-95.

2009a. Sobre la composición y la disposición en el arte rupestre de Chile: Consideraciones metodológicas. Magallania 37 (1): 19-38.

2009b.Social interaction and early rock art styles in the Atacama Desert (Northern Chile). Antiquity 83: 619-633.

GALLARDO, F., y P. DE SOUZA, 2008. Rock art, modes of production and social identities during the Early Formative Period in the Atacama Desert (Northern Chile). En Archaeologies of art: Time, place, and identity, I. Domingo, D. Fiore \& S. May (Eds.), pp. 79-97. One World Archaeology, Left Coast Press, California.

GALLARDO, F., y H. D. YACOBACCIO, 2005. Wild or domesticated? Camelids in Early Formative rock art of the Atacama Desert (Northern Chile). Latin American Antiquity 16 (2): 115-130.

GALLARDO, F., L. CORNEJO, R. SÁNCHEZ, B. CASES, A. ROMÁN y A. DEZA, 1993. Arqueología en el valle de Quillagua, río Loa, Norte de Chile. Gaceta Arqueológica Andina 23: 125-138.

GALLARDO, F., SINCLAIRE, C. y C. SILVA, 1999. Arte rupestre, emplazamiento y paisaje en la cordillera del desierto de Atacama. En Arte rupestre en los Andes de Capricornio, J. Berenguer y F. Gallardo (Eds.), pp. 57-96. Museo Chileno de Arte Precolombino, Santiago.

GAMBLE, C., 1982. Interaction and Alliance in Palaeolithic Society. Man 1: 92-107.

GONZÁLEZ, C., y K. WESTFALL, 2010. Cementerio Regimiento de Chorrillos de Calama: Testimonios funerarios formativos en el Loa Medio, región de Antofagasta. En Actas del XVII Congreso de Arqueología Chilena, vol. 1, pp. 95-105. Ediciones Kultrún, Valdivia.

HIDALGO, J., 1984. Complementariedad ecológica y tributo en Atacama. 1683-1792. Estudios Atacameños 7: 422-470.
HORNKOHL, H., 1954-1955. Los petroglifos de Gatico en la provincia de Antofagasta, Chile. Revista Chilena de Historia Natural 54 (12): 152-154.

HORTA, H., 2001. Sectorización de estilos en el arte rupestre del Loa, norte de Chile. En Segundas Jornadas de Arte y Arqueología, J. Berenguer, L. Cornejo, F. Gallardo y C. Sinclaire (Eds.), pp. 85108. Museo Chileno de Arte Precolombino, Santiago.

LATCHAM, R., 1933. Notas preliminares de un viaje arqueológico a la localidad de Quillagua. Revista Chilena de Historia y Geografía XXXVII: $130-138$.

1938. La arqueología de la región atacameña. Prensas de la Universidad de Chile, Santiago.

LLAGOSTERA, A., 1996. San Pedro de Atacama: Nodo de complementariedad reticular. En La integración surandina cinco siglos después, X. Albó, M. Aratia, J. Hidalgo, L. Núñez, A. Llagostera, M. Remy y B. Revesz (Comps.), pp. 17-42. Universidad Católica del Norte y Centro de Estudios Regionales Andinos Bartolomé de las Casas, Estudios y Debates Regionales Andinos 91, Cusco.

2004. Los antiguos habitantes del Salar de Atacama. Pehuén Editores, Santiago.

MARQUET, P., F. BOZINOVIC, G. BRADSHAW, C. CORNELIUS, H. GONZÁLEZ, J. GUTIÉRREZ, E. HAJEK, J. LAGOS, F. LÓPEZ-CORTÉS, L. NÚÑEZ, E. ROSELLO, C. SANTORO, H. SAMANIEGO, V. STANDEN, J. TORRES-MURA, y F. JAKSIC, 1998. Los ecosistemas del desierto de Atacama y área andina adyacente en el norte de Chile. Revista Chilena de Historia Natural 71: 593-617.

MARTÍNEZ, J. L., 1985a. Información sobre el comercio de pescado entre Cobija y Potosí, hecha por el Corregidor de Atacama, Don Juan Segura (19 de julio de 1591). Cuadernos de Historia 5: 161-171.

1985b. La formación del actual pueblo de Toconce. Siglo XIX. Chungara 15: 99-124.

1990. Interetnicidad y complementariedad en el altiplano meridional: el caso atacameño. Andes 1: 11-30.

1998. Pueblos del chañary el algarrobo: Los Atacamas en el siglo XVII. DIBAM, Santiago.

MOSTNY, G., y H. NIEMEYER, 1983. Arte rupestre chileno. Ministerio de Educación, Departamento de Extensión Cultural, Santiago.

1984. Arte rupestre en El Medano, II Región. Creces 9 (5): 2-5. 
NIEMEYER, H., 2010. Crónica de un descubrimiento. Las pinturas rupestres de ElMédano, Taltal. Museo Chileno de Arte Precolombino, Santiago.

NIEMEYER, H., y V. SCHIAPPACASSE, 1981. Aportes al conocimiento del Período Tardío del extremo Norte de Chile: Análisis del sector Huancarane del valle de Camarones. Chungara 7: 3-103.

NÚÑEZ, L., 1971. Secuencia y cambio en los asentamientos humanos de la desembocadura del río Loa en el Norte de Chile. Boletín de la Universidad de Chile 112: 3-25.

1976. Geoglifos y tráfico de caravanas en el desierto chileno. En Homenaje al Dr. R.P. Gustavo Le Paige, s.j., H. Niemeyer (Ed.), pp. 147-201. Universidad del Norte, Antofagasta.

1984a. Secuencia de asentamientos prehistóricos del área de Taltal. Futuro 8: 28-76.

1984b. Pircas: Ocupación temprana en el norte de Chile. Gaceta Arqueológica Andina 11: 8-9.

1985. Petroglifos y tráfico en el desierto chileno. En Estudios en arte rupestre, C. Aldunate, J. Bereguer y V. Castro (Eds.), pp. 243264. Museo Chileno Arte Precolombino, Santiago.

1992. Ocupación arcaica en la Puna de Atacama: secuencia, movilidad y cambio. En Prehistoria Sudamericana. Nuevas perspectivas, B. Meggers (Ed.), pp. 283-308. Taraxacum, Washington.

NÚÑEZ, L., y L. BRIONES, 1967-68. Petroglifos del sitio Tarapacá -47 (Provincia de Tarapacá). Estudios Arqueológicos 3-4: 43-75.

NÚÑEZ, L., y T. DILLEHAY, 1995 [1979]. Movilidad giratoria, armonía social y desarrollo en los Andes Meridionales: patrones de tráfico e interacción económica (Ensayo). Dirección General de Investigaciones Científicas y Tecnológicas, Universidad del Norte, Antofagasta.

NÚÑEZ, L., P. DE SOUZA, I. CARTAJENA y C. CARRASCO, 2007. Quebrada de Tulán: evidencias de interacción circunpuneña durante el Formativo Temprano en el sureste de la cuenca de Atacama. En Producción y circulación prehispánicas de bienes en el sur andino, tomo II, A. Nielsen, M. C. Rivolta, V. Seldes, M. M. Vázquez y P. H. Mercolli (Eds.), pp. 287-304. Colección Historia Social Precolombina, Editorial Brujas, Córdoba.

NÚÑEZ, L., I. CARTAJENA, P. DE SOUZA y C. CARRASCO, 2009. Los estilos Confluencia y Taira Tulán: ritos rupestres del Formativo Temprano en el sureste del Salar de Atacama. En Crónicas sobre la piedra. Arte Rupestre de las Américas, M. Sepúlveda, L. Briones y J. Chacama (Eds.), pp. 205-220. Ediciones Universidad de Tarapacá, Tarapacá.
NÚÑEZ, L., I. CARTAJENA, J. LOO, S. RAMOS, T. CRUZ y H. RAMÍREZ, 1997. Registro e investigación del arte rupestre en la Cuenca de Atacama (Informe Preliminar). Estudios Atacameños 14:307-325.

NÚÑEZ, P., y R. CONTRERAS, 2006. El arte rupestre de Taltal, norte de Chile. Actas del V Congreso Chileno de Antropología, pp. 348-357. Colegio de Antropólogos de Chile, San Felipe.

PHILIPPI, R., 1860. Viage al Desierto de Atacama hecho de orden del gobierno de Chile. Librería Eduardo Anton, Halle in Sajonia.

PIMENTEL, G., C. REES, P. DE SOUZAy L. ARANCIBIA, 2011. Viajeros costeros y caravaneros. Dos estrategias de movilidad en el período Formativo del desierto de Atacama, Chile. En Ruta. Arqueología, historia y etnografía del tráfico sur andino, L. Núñez y A. Nielsen (Eds.), pp. 43-81. Encuentro Grupo Editor, Córdoba.

PIMENTEL, G., e I. MONTT, 2008. Tarapacá en Atacama. Arte Rupestre y relaciones intersocietales entre el 900 y 1450 DC, Boletín del Museo Chileno de Arte Precolombino 13 (1):35-50.

PLOG, S., 1978. Social interaction and stylistic similarity: a reanalysis. En Advances in archaeological method and theory, vol. 1, M. Schiffer (Ed.), pp 143-182. Academic Press, New York.

POLLARD, G., 1970. The cultural ecology of ceramic-stage settlement in the Atacama desert. University Microfilms, Ann Arbor.

REES, C., y P. DE SOUZA, 2004. Producción lítica durante el Período Formativo en la Subregión del río Salado. Chungara 36 (número especial 1): 453-465.

ROJAS, O., 2005. El arte rupestre en el valle de Lasana. Comisión Nacional del Medio Ambiente, Antofagasta.

SEELENFREUND, A., C. SINCLAIRE, P. DE SOUZA, M. DINATOR, E. FONSECA, M. CHESTA y J. MORALES, 2004. Caracterización de lavas vítreas de fuentes y sitios arqueológicos del Formativo Temprano en la Subárea Circumpuneña: Resultados preliminares y proyecciones para la prehistoria atacameña. Estudios Atacameños 28: 45-57.

SEPÚlVEDA, M., 2002. Imagen y Espacialidad en el Desierto de Atacama Durante los Períodos Tardíos (950-1.550 DC). Memoria para optar al título de Arqueóloga. Departamento de Antropología, Universidad de Chile, Santiago.

2004. Esquemas Visuales y Emplazamiento de las representaciones rupestres de camélidos del Loa superior en tiempos incaicos. ¿Una nueva estrategia de incorporación de este territorio al Tawantinsuyu? Chungara 36 (2): 439-451. 
2006. Nuevas formas de ver, nuevas formas de hacer: análisis formal y de composición de las tabletas de râpé de la localidad del río Salado (II región, norte de Chile). En Actas del III Jornadas de Historia del Arte, J. M. Martínez (Ed.), pp. 49-61. Universidad Adolfo Ibáñez, RIL Editores, Santiago.

2008. Arte rupestre en tiempos incaicos: nuevos elementos para una vieja discusión. En Lenguajes Visuales de los Incas, P. González y T. Bray (Eds.), pp. 111-124. BAR International Series 1848, Archaeopress, Oxford.

2011. Arte rupestre y Complejidad social durante el período Intermedio Tardío, en la localidad del río Salado (norte de Chile). Chungara 43 (1): 53-72.

2012 Ms. Pinturas rupestres, tecnología y flujos de información en el desierto de Atacama, norte de Chile. Manuscrito en poder del autor.

SEPÚlVEDA, M., ROMERO, A. y L. BRIONES, 2005. Tráfico de caravanas, arte rupestre y ritualidad en la quebrada de Suca (extremo norte de Chile). Chungara 37 (2): 225-243.

SINCLAIRE, C., 1999. Pinturas rupestres y textiles formativos en la región atacameña. Estudios Atacameños 14:327-338.

2004. Prehistoria del período formativo en la cuenca alta del río Salado (Región del Loa superior). Chungara 36 (número especial 2): 619-639.

TARRAGÓ, M., 1984. La historia de los pueblos circumpuneños en relación con el altiplano y los Andes meridionales. Estudios Atacameños 7: 116-132.
TOLOSA, B., 1967. Descripción de los petroglifos de la zona de arqueológica de Tamentica. Revista de la Universidad del Norte 3:3-12.

URIBE, M., 1999. La cerámica de Arica 40 años después de Dauelsberg. Chungara 31 (2): 189-228.

2006. Sobre cerámica, su origen y complejidad social en los Andes del Desierto de Atacama. En Esferas de interacción prehistóricas y fronteras nacionales modernas: Los Andes sur centrales, $\mathrm{H}$. Lechtman (Ed.), pp. 449-502. Instituto de Estudios Peruanos, Lima.

URIBE, M., y L. ADAN, 2004. Acerca Del Dominio Inka, Sin Miedo, Sin Vergüenza. Chungara 36 (número especial 1): 467-480.

URIBE, M., y P. AYALA, 2004. La alfarería de Quillagua en el contexto formativo del Norte Grande de Chile (1000 AC-500 DC). Chungara 36 (número especial 2): 585-598.

VILCHES, F., y G. CABELLO, 2011. Variaciones sobre un mismo tema: el arte rupestre asociado al complejo Pica- Tarapacá, norte de Chile. Chungara 43 (1): 37-52.

VILCHES, F., y M. URIBE, 1999. Grabados y pinturas del arte rupestre Tardío de Caspana. Estudios Atacameños 18: 73-87.

WOBST, M., 1977 Stylistic behavior and information exchange. En For the Director: Research Essays in Honor of James B. Griffin, Charles E. Cleland (Ed.), pp. 317-42. Museum of Anthropology, University of Michigan, Ann Arbor.

YACOBACCIO, H., 2004. Social dimensions of camelid domestication in the southern Andes. Anthropozoologica 39: 237-247. 